\title{
Elimination diet and the development of multiple tree-nut allergies
}

\author{
Arnon Elizur ${ }^{1}$, Jennifer B. Bollyky ${ }^{1}$ and Whitney M. Block ${ }^{1}$
}

BACKGROUND: Despite its high prevalence, relatively little is known about the characteristics of patients with multiple treenut allergies.

METHODS: Patients ( $n=60$, aged $4-15$ years), recruited for a multiple food (tree nuts, peanut, milk, egg, soy, sesame, and wheat) oral immunotherapy (OIT) study, filled a questionnaire on their initial allergy evaluation. Medical records were reviewed. At OIT enrollment (median interval, 7.5 years), patients underwent oral food challenges (OFCs) to foods still eliminated.

RESULTS: There was significantly less evidence for eliminating tree nuts compared with other foods, as reflected by a lower rate of acute reaction to the offending food, either as the trigger for initial allergy evaluation (5.9\% for tree-nuts vs. 20-40\% for other foods, respectively $P<0.001$ ) or later in life (14.5\% vs. $38-75 \%$, respectively $P=0.001)$, and a higher rate of negative skin prick test (SPT)/specific lgE (slgE) at initial diagnosis (25\% vs. $<10 \%, P<0.001)$. SPT/slgE increased significantly from past initial levels to present for tree nuts $(P<0.001)$ and peanut $(P=0.001)$ but not for other foods, and most OFCs performed at present were positive.

CONCLUSIONS: Tree nuts are often eliminated from the diet of multiple-food-allergic patients, despite their low probability for allergy. Sensitization and allergy to most tree nuts exist years later, suggesting that it developed during the period of elimination.

I t is estimated that $2.4 \%$ of the population and $30.4 \%$ of patients with food allergy suffer from multiple food allergies $(1,2)$. A higher frequency of multiple food allergies has been described in certain populations. Patients with peanut allergy were reported to have high sensitization rates, reaching up to $86 \%$, to tree nuts and to frequently have concomitant clinical allergy $(3,4)$. Also, patients who are allergic to a single tree nut are frequently sensitized to additional tree nuts, and sensitization to other tree nuts among tree-nut-allergic children has already been detected at age $<1$ year in $25 \%$ of patients (5). Patients with atopic dermatitis, especially those with moderate-to-severe disease, comprise another group with a high frequency (up to 30\%) of multiple food allergies, and they are frequently sensitized to multiple foods $(6,7)$.

Self-reported food allergy is subjective and inaccurate (8), and testing for food-specific IgE by skin test or in vitro laboratory testing is only moderately specific $(1,9)$. Therefore, a double-blind, placebo-controlled food challenge, or alternatively an open oral food challenge (OFC), is recommended before food allergy is diagnosed and an elimination diet is initiated (10). However, OFCs are time-consuming, often associated with adverse events, and are not without risks $(11,12)$. Therefore, OFCs might be difficult to perform on a child with multiple sensitizations. As a result, detecting multiple sensitizations in a child might lead to an extensive elimination diet.

Prescribing an extensive elimination diet for a child without rigorously confirming its need may significantly impair the child's nutritional needs (13) as well as quality of life (14). Moreover, recent data suggest that eliminating peanuts from the diet may in itself increase the risk of developing IgEmediated peanut allergy $(15,16)$.

Given the increased prevalence of multiple food allergies and the risks of extensive elimination diet, it is important to understand "real-life" approaches by allergists and pediatricians to the diagnosis of patients with multiple food allergies and to prescribing an elimination diet. The goal of the present study was to examine the history of a selected group of patients who are currently diagnosed with multiple food allergies and are enrolled in a multiple food oral immunotherapy research, including the reasons for elimination of individual foods, evidence and level of previous sensitization, and documented reactions.

\section{METHODS}

\section{Patients}

This study is the baseline description of 60 patients, $>4$ years old, enrolled to multiple oral immunotherapy treatment research programs. For inclusion, patients had to have the skin prick test (SPT) $\geq 6 \mathrm{~mm}$ wheal diameter or $\operatorname{sIgE}>4 \mathrm{kU} / \mathrm{l}$ (ImmunoCAP) and to react to $\leq 500 \mathrm{mg}$ cumulative food protein on a double-blind, placebo-controlled food challenge to at least two of the following allergens: peanut, milk, egg, soy, sesame, wheat, cashew, walnut, hazelnut, and almond. SPT and SIgE were performed to pistachio and pecan as well, and food challenges were conducted for patients 


\section{Articles $\mid$ Elizur et al.}

fulfilling the inclusion criteria. Information on demographics and past medical history was obtained from all patients, including age and reason for elimination of each food from the diet, occurrence and nature of previous adverse reactions, and OFCs performed. Patients' medical records were reviewed and SPTs and sIgE levels, from the time food elimination was initiated, were collected. The study was approved by the Stanford IRB committee.

\section{Skin Prick Tests}

Past SPTs, performed when elimination diet was initiated, were done by local allergists and documents were reviewed by an allergy specialist (A.E.). Current SPTs were performed by trained staff with the following extracts: peanut $(1: 20 \mathrm{w} / \mathrm{v})$, almond $(1: 20 \mathrm{w} / \mathrm{v})$, pecan $(1: 20 \mathrm{w} / \mathrm{v})$, milk $(1: 20 \mathrm{w} / \mathrm{v})$, sesame seed $(1: 20 \mathrm{w} / \mathrm{v})$, egg white $(1: 20 \mathrm{w} / \mathrm{v})$, cashew $(1: 20 \mathrm{w} / \mathrm{v})$, walnut $(1: 20 \mathrm{w} / \mathrm{v})$, whole wheat $(1: 20 \mathrm{w} / \mathrm{v})$, hazelnut $(1: 20 \mathrm{w} / \mathrm{v})$, soybean $(1: 40 \mathrm{w} / \mathrm{v})$ (Greer Laboratories, Lenoir, NC), and pistachio (1:10 w/v, ALKPort, Washington, NY). Histamine $(10 \mathrm{mg} / \mathrm{ml}$, Hollister-Stier, Spokane, WA) was used as a positive control and physiological saline as a negative control.

\section{Food Challenges}

All food challenges performed during oral immunotherapy enrollment were performed at SNP Center for Allergy and Asthma Research at Stanford University under medical supervision, and patients were observed for at least $2 \mathrm{~h}$ after the last dose. Seven doses of food allergens were given every 15-30 min in increasing amounts $(5,20,50,100,100,100$, and $125 \mathrm{mg})$ up to a cumulative total of $500 \mathrm{mg}$ of protein. Reactions during each OFC were scored based on modified Bock's criteria (17) and treated according to the guidelines (10).

\section{Statistical Analysis}

Statistical analyses were performed using SPSS software (version 20; SPSS, Chicago, IL). The Mann-Whitney test was used for nonnormally distributed continuous variables. Fisher's exact test was used to analyze differences in categorical variables. Kruskal-Wallis test was performed to analyze differences between multiple continuous variables. All analyses were two-tailed and a $P$-value of $<0.05$ was considered significant. Bonferroni correction was applied when multiple comparisons were made. For the purpose of statistical analysis, SPT wheal size $(\mathrm{mm})$ and sIgE levels (kIU/l) from the time patients were diagnosed were categorized as follows: grade $0(\mathrm{SPT}=0$ and $\operatorname{sIgE}<0.35)$, grade $1(1 \leq \mathrm{SPT} \leq 4$ or $0.35<\operatorname{sIgE} \leq 3.5)$, grade 2 $(5 \leq \mathrm{SPT} \leq 8$ or $3.5<\operatorname{sIgE} \leq 17.5)$, and grade 3 ( $\mathrm{SPT}>8$, $\operatorname{sIgE}>17.5)$. Grading was done based on levels that were previously described as significant (18-20), and the highest grade (SPT vs. sIgE) was used for the analysis.

\section{RESULTS}

Patient age ranged between 4 and 15 years with a median of 8 and most of the patients were White or Asian (Table 1). Most patients had other allergic comorbidities, in addition to food allergy. Atopic dermatitis was the most frequent (76.7\%) comorbidity, and, in case of $31.7 \%$ of the patients, it was felt to be triggered/exacerbated by the allergenic food. An acute reaction to a single food item was the most common trigger for allergy evaluation, at time of initial diagnosis, accounting for $70 \%$ of the cases. Milk $(n=11)$, peanut $(n=9)$, and a single tree nut $(n=15)$ were the most frequent triggers. In six patients (10\%), the reaction occurred to a mixture of foods and an individual trigger could not be identified. Allergy tests were performed solely because of eczema in nine patients $(13 \%)$ and in additional 7\% because of other reasons (family history of food allergy, $n=2$; rectal bleeding, $n=1$; and occasional vomiting not related to food, $n=1$ ). Following
Table 1. Demographics of the study population

\begin{tabular}{lc}
\hline Variable $(n=60)$ & Mean \\
\hline Age (years) & $8.6 \pm 3.1$ \\
Male gender & $30(50 \%)$ \\
& \\
Race $^{\mathrm{a}}$ & \\
White & $41(68 \%)$ \\
African American & $2(3.3 \%)$ \\
Asian & $28(47 \%)$ \\
Other & $3(5 \%)$ \\
Number of food items ever eliminated from diet & $8 \pm 1.7$
\end{tabular}

\section{Atopic dermatitis}

Diagnosed

$46(77 \%)$

Age at diagnosis

$0.85 \pm 1.5$

Resolved no.

$19(41 \%)$

Age of resolution

$2.5 \pm 2.2$

Asthma

Total

$29(48 \%)$

Age at diagnosis

$3.2 \pm 2.8$

\begin{tabular}{lc} 
Allergic rhinitis & \\
Total & $45(75 \%)$ \\
Age at diagnosis & $4 \pm 2.2$ \\
& \\
Family history & \\
Allergic rhinitis & $57 \%$ \\
Asthma & $25 \%$ \\
Food allergy & $30 \%$ \\
Eczema & $18 \%$ \\
\hline${ }^{a}$ Numbers add up to $>60$ because some subjects self-identify with $>1$ race.
\end{tabular}

their initial allergy evaluation and initial SPT/sIgE tests, and although a reaction to a single food was often documented, patients were instructed to eliminate a median of 8 foods (range, 2-11) from their diet. Cashew, hazelnut, pecan, pistachio, and walnut were each eliminated by 58 patients, peanut by 50 patients, almond by 47 patients, milk by 29 patients, egg by 30 patients, soy by 9 patients, sesame by 23 patients, and wheat by 5 patients. Of the 220 foods that were eliminated without evidence of a previous reaction, all cases of milk, soy, and egg elimination began before age 1.5 years. Most peanuts and tree nuts were eliminated before age 4 years, when, according to previous guidelines, introduction, especially to atopic children, was not yet recommended. Only five patients had allergy evaluation for specific foods beyond the age of 4 years. In two patients, eliminated foods were not introduced at home because of allergic siblings; in one case, a deliberate elimination of peanuts and all tree nuts was done 


\section{Multiple tree-nut allergy Articles}

by the mother, without allergy evaluation, following a reaction to cashew in infancy, and two patients eliminated sesame without allergy testing because of peanut and tree-nut allergies and were diagnosed later with sesame allergy. Therefore, it seems likely that patients were not consuming any of the eliminated foods before initiation of elimination diet.

We then examined reasons for initiation of elimination diet for each of the eliminated foods. A previous reaction was the most common reason accounting for the elimination of milk (55\%), but it was much less frequent $(20-30 \%)$ in the case of most other foods. Elimination of individual tree nuts was done in $>40 \%$ of cases because of a fear of crosscontamination by another tree nut or peanut to which the patient reacted to, whereas a reaction to the same tree nut was documented in only $5.9 \%$ of the cases (Figure 1a). In many patients (35-80\%), sensitization alone (defined as SPT/ $\operatorname{sIgE} \geq$ grade 1) with no documented reaction was the reason for elimination.

SPT and sIgE performed when patients' allergy was first diagnosed were available in 51/60 patients and for a total of 320 food allergens (Figure 1b). Although for most allergens tested, SPT or sIgE was at grade 2-3 levels (SPT wheal size $>4 \mathrm{~mm}$ or sIgE $>3.5 \mathrm{kIU} / \mathrm{l}$ ), many patients had absence of or low sensitization. In the case of tree nuts, SPT/sIgE were negative in almost $25 \%$ of the cases, and additional $32 \%$ patients were in grade 1 levels (Figure 1b). A total of 47 patients were diagnosed with atopic dermatitis (AD) or egg allergy in infancy. In 15 of those, peanut sensitization in infancy was within the inclusion criteria for the LEAP study and $7(46 \%)$ had peanut allergy at study entry. To include only patients with more severe form of $\mathrm{AD}$, we excluded patients whose $\mathrm{AD}$ was resolved by study entry. A total of 34 patients were categorized as having severe $\mathrm{AD}$ or egg allergy. In 10 of those, peanut sensitization in infancy was within the entry threshold for the LEAP study, and $5(50 \%)$ of the patients had peanut allergy at study entry.

Of the 50 patients who eliminated peanut from the diet, 6 (12\%) eliminated soy because of sensitization alone. Of those, 4 patients resumed soy consumption later in life with no adverse effects. Of the 2 patients who were still eliminating soy at study entry, 1 was found allergic to soy and the other was not challenged because of minimal sensitization and is likely not allergic. These data suggest that unlike peanuts and tree nuts, elimination of soy is less likely to lead to soy allergy.

A reaction, either before the diagnosis was made or as a result of an accidental exposure later in life, occurred in $76 \%$ of milk-allergic patients, but it occurred in only $30-40 \%$ patients in the case of most foods and in only $14.5 \%$ of the children eliminating tree nuts (Table 2). No significant difference was noted in the severity of reactions experienced to the different foods, as measured in the percentage of reactions treated with injectable epinephrine. Reactions due to accidental exposures to foods eliminated solely on the basis of sensitization or cross-contamination fear were experienced for walnut by $10 / 52$ patients (19.2\%, 2 required epinephrine), peanut $-6 / 37$ (16.2\%, 1 required epinephrine), almond $-1 / 48$
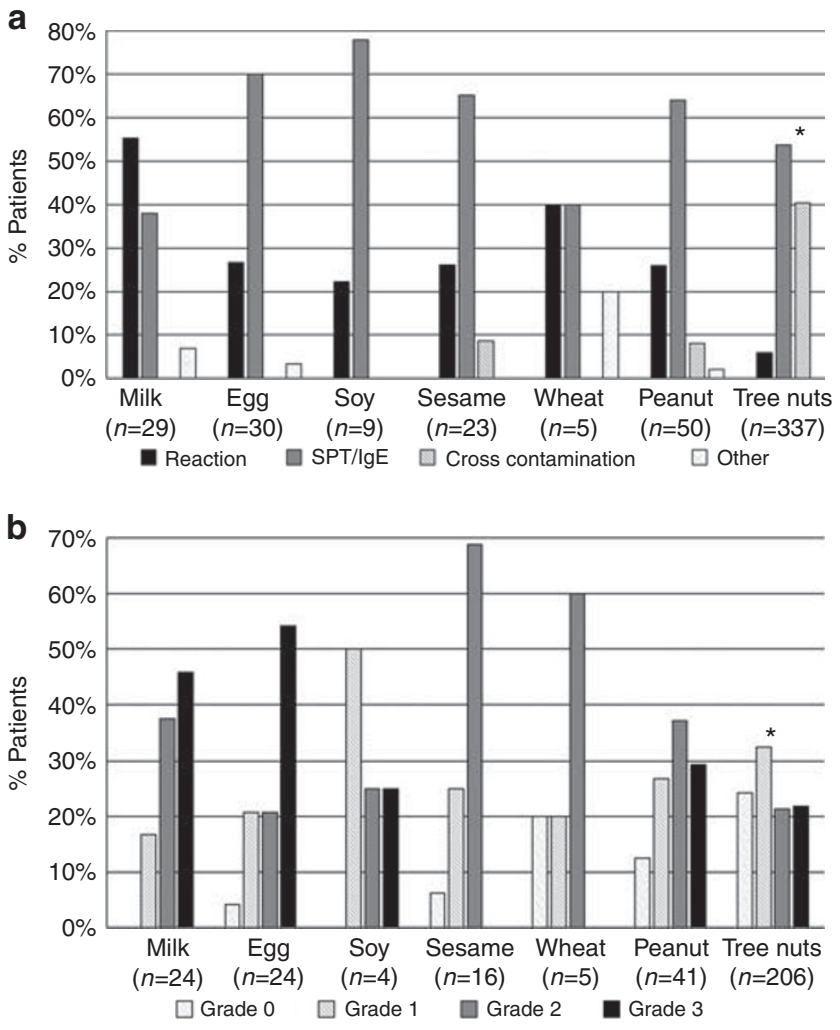

Figure 1. Triggers for elimination and baseline SPT or slgE individual foods. Reasons for elimination (a) and baseline SPT and slgE levels (b) (grade $0 ; \mathrm{SPT}=0$ and slgE $<0.35$, grade $1 ; 1 \leq \mathrm{SPT} \leq 4$ or $0.35<\operatorname{slgE} \leq 3.5$, grade $2 ; 5 \leq \mathrm{SPT} \leq 8$ or $3.5<\operatorname{slgE} \leq 17.5$, and grade 3 ; $\mathrm{SPT}>8$, slgE $>17.5$ ) to each food were compared and Bonferroni correction applied.

* Statistically significant differences were found between tree nuts and egg, milk, peanut, sesame, or wheat (a) and between tree nuts and milk or sesame (b).

(2\%, no epinephrine required), cashew-12/50 (24\%, 4 required epinephrine), hazelnut-0/58, pecan $-3 / 56$ (5.4\%, 2 required epinephrine), pistachio-4/55 (7.3\%, 2 required epinephrine), milk-7/14 (50\%, 5 required epinephrine), egg $-5 / 23$ (21.7\%, 1 required epinephrine), soy-1/7 (14.3\%, no epinephrine required), sesame-3/17 (17.6\%, no epinephrine required), and wheat $-0 / 3$. Of the few OFC reported by the patients to be previously performed by local allergists at the time of first allergy evaluation, most were negative. Reintroduction of eliminated food was relatively frequent (50$60 \%$ ) among milk-, soy-, and wheat-allergic patients, but it was much lower in the case of egg and lowest for sesame, peanut, and tree nuts (Table 2).

When examining the different tree nuts separately, we found that a reaction led to the diagnosis of cashew allergy more often than for other tree nuts, but even for cashew it accounted for only $14 \%$, and the difference from other tree nuts was not statistically significant (Figure 2a). Interestingly, in this cohort of multiple-food-allergic patients, a reaction as a reason for initiating elimination was documented in only a single patient in the case of almond and in none in hazelnut (Figure 2b). SPT or sIgE levels were comparable for most 


\section{Articles | Elizur et al.}

Table 2. Characteristics of foods initially eliminated from patients' diet

\begin{tabular}{|c|c|c|c|c|c|c|c|}
\hline Variable & Tree nuts & Peanut & Milk & Egg & Soy & Sesame & Wheat \\
\hline Ever eliminated, $n$ & 337 & 50 & 29 & 30 & 9 & 23 & 5 \\
\hline Age at elimination (Years) (Median, range) & $1.2(0.1-9)$ & $1.1(0.3-8)$ & $0.8(0.1-1.3)$ & $1.0(0.3-2)$ & $1.0(0.3-9)$ & $2.0(0.3-11)$ & $0.8(0.3-1)$ \\
\hline Male gender (\%) & 51 & 50 & 62 & 67 & 56 & 74 & 80 \\
\hline \multicolumn{8}{|l|}{ Race } \\
\hline White (\%) & 71 & 68 & 69 & 77 & 78 & 74 & 100 \\
\hline Asian (\%) & 46 & 50 & 45 & 37 & 44 & 35 & 20 \\
\hline Other (\%) & 6.8 & 6 & 10 & 13 & 0 & 8.7 & 40 \\
\hline Reaction ever (\%) & 14 & 38 & 76 & 40 & 33 & 39 & 40 \\
\hline Reaction-skin $(\%)^{b}$ & 79 & 65 & 74 & 76.9 & 67 & 89 & 50 \\
\hline Reaction-GI (\%) ${ }^{\mathrm{b}}$ & 49 & 61 & 52 & 53.8 & 67 & 11 & 50 \\
\hline Reaction-resp. $(\%)^{\mathrm{b}}$ & 39 & 22 & 39 & 38.5 & 33 & 11 & 0 \\
\hline Reaction-Epi $(\%)^{\text {b }}$ & 24 & 12 & 17 & 25 & 33 & 0 & 0 \\
\hline OFC ever $(\%)^{c}$ & 16 & 18 & 43 & 43.3 & 44 & 22 & 60 \\
\hline Positive OFC & $5 / 53$ & $2 / 9$ & $2 / 13$ & $4 / 13$ & $0 / 5$ & $0 / 5$ & $1 / 4$ \\
\hline Food re-introduction $(\%)^{d}$ & 14 & 12 & 48 & 30 & 56 & 17 & 60 \\
\hline Current elimination, $n$ & 289 & 44 & 15 & 21 & 4 & 19 & 2 \\
\hline
\end{tabular}

Gl, gastrointestinal; Resp, respiratory; EPI, epinephrine.

$P$-value $<0.00238$ (after applying Bonferroni correction) is considered significant.

a Significant differences between tree nuts and egg, milk, or peanut and between peanut and milk.

${ }^{b}$ Initial reaction and the percentage is of number of patients with reactions.

'Significant differences between tree nuts and egg and milk.

${ }^{\mathrm{d}}$ Significant differences between tree nuts and milk, and between peanut and milk

tree-nuts (Figure 2b). However, SPT/sIgE levels for cashew, pistachio, and walnuts were higher compared with other tree nuts. That difference was statistically significant only compared with almonds (Figure $\mathbf{2 b}$ ). Although a reaction, either before the diagnosis was made or as a result of an accidental exposure later in life, was not frequent in all those with tree-nut allergies as a group, it occurred significantly more in the case of cashew (34\%) and walnut $(26 \%)$ as compared with most other nuts (0-12\%) (Table 3).

Finally, patients' SPT/sIgE levels were compared, between levels from the time patients were first diagnosed and the current levels obtained on enrollment (available for 252 allergens). Although no significant differences in SPT/sIgE grades were noted from time of diagnosis to time of enrollment for egg, milk, and sesame, grades were significantly higher on enrollment for peanut $(P=0.001)$ and treenuts $(P<0.001)$ (Figure 3$)$. Of the 41 patients with initially negative SPT/sIgE grades to tree nuts, 27 became positive at enrollment ( 8 became grade 1, 10 grade 2, and 9 grade 3 ). Significant increases in the rate of grades $2-3$ sensitization level was noted for: almond-from 16 to $79 \%, P<0.001$; cashew-from 63 to $91 \%, P=0.017$; hazelnut, from 48 to $81 \%$, $P=0.017$; and pistachio-from 70 to $100 \% \quad(P=0.029)$ (Figure 3).
OFCs performed at present for foods that were still eliminated, and fulfilling inclusion criteria, were positive for most foods: cashew $(n=46 / 47)$, pistachio $(n=42 / 42)$, hazelnut $(n=30 / 42)$, walnut $(n=32 / 35)$, pecan $(n=29 / 30)$, almond $(n=10 / 21)$, peanut $(n=36 / 41)$, egg $(n=19 / 19)$, milk $(n=14 / 16)$, sesame $(N=11 / 14)$, and soy and wheat $(n=2 / 2$ each $)$.

\section{DISCUSSION}

The aim of this study was to examine "real-life" approaches for food elimination in multiple-food-allergic patients. We found that elimination of tree nuts was unique in several aspects. First, a documented reaction was rare in the case of tree nuts and their elimination was often based on fear of cross-contamination with another allergenic food. Second, overuse of allergy testing might lead to the diagnosis of multiple sensitizations, often minimal, leading in turn to unnecessary elimination diet early in life. Sensitization levels increased significantly years later, for peanut and tree nuts in particular, and most OFCs performed at present were positive, suggesting that some tree-nut allergies developed during the period of elimination diet.

Certain scenarios exist in which the consensus recommendation, to diagnose food allergy based on a previous reaction 


\section{Multiple tree-nut allergy $\mid$ Articles}
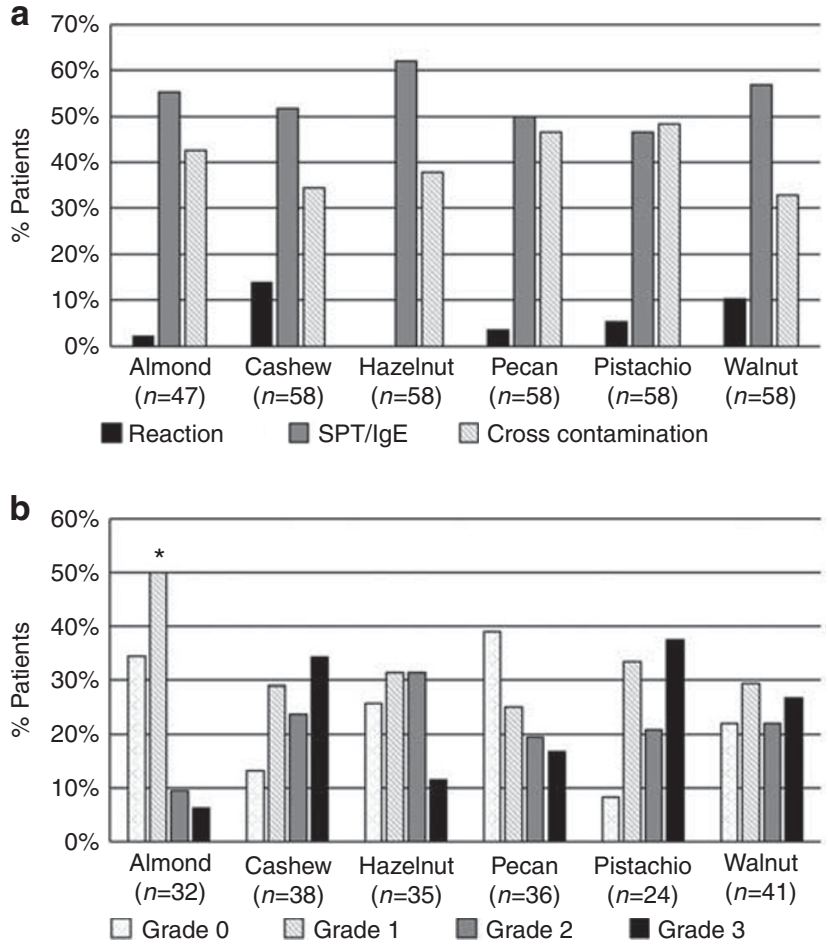

Figure 2. Triggers for elimination and baseline SPT or slgE for individual tree nuts. Reasons for elimination (a) and baseline SPT/slgE levels (b) (grade $0 ; \mathrm{SPT}=0$ and $\mathrm{slgE}<0.35$, grade $1 ; 1 \leq \mathrm{SPT} \leq 4$ or $0.35<\operatorname{slg} \mathrm{E} \leq 3.5$, grade $2 ; 5 \leq \mathrm{SPT} \leq 8$ or $3.5<\operatorname{sigE} \leq 17.5$, and grade 3 ; $\mathrm{SPT}>8$, slgE $>17.5$ ) to each tree nut were compared and Bonferroni correction applied. *Statistically significant differences were found between almond and cashew, pistachio, or walnut (b).

or a positive OFC, becomes controversial. For example, some recommend avoidance of all tree nuts by young children with peanut allergy because of practical concerns about crosscontamination (9). Others claim that a child with peanut allergy who is not allergic to tree nuts should not be required to avoid individual tree nuts, hypothesizing that oral exposure to a certain food enables acquisition of tolerance to it (21). A similar controversy exists in patients with a single tree-nut allergy with respect to avoidance of other tree nuts (22). Infants with $\mathrm{AD}$ comprise another group of patients around which controversy exists. Although food allergens are considered a significant trigger for $\mathrm{AD}$ in $30-40 \%$ of patients, some guidelines advise to avoid routine testing in such children before introducing highly allergenic foods, such as milk, egg, or peanut into their diet $(10,23)$. However, children with $\mathrm{AD}$ without IgE-mediated food allergy might develop life-threatening food allergy following elimination of certain foods from the diet (7). Our study demonstrates that OFCs were rarely performed in this group of multiple foodsensitized patients despite the fact that acute reaction was not documented for most eliminated foods. This suggests that overuse of allergy testing by pediatricians and allergists, might lead to overdiagnosis of food sensitizations, particularly in patients with $\mathrm{AD}$. Once sensitization is documented, multiple
OFCs are difficult to perform resulting in an extensive elimination diet.

A SPT wheal size and sIgE level thresholds that would predict a positive food challenge have been reported for some foods (peanut, egg, and milk), but attempts to provide similar predictive values for other foods in general, and specifically for tree nuts, have failed $(4,9,24)$. Although a negative SPT provides useful information in ruling out IgE-mediated allergy to a specific food, a negative $\operatorname{sIgE}$ does not $(9,24,25)$. SPT/sIgE levels in many of our patients, and particularly in the case of tree nuts, were negative, or between 0.35 and $3.5 \mathrm{kU} / \mathrm{l}$ (much lower than the threshold levels used for milk, egg, or peanut for predicting a positive OFC). Therefore, many of the foods eliminated, particularly tree nuts, might not have been allergenic at first.

Compared with other foods, SPT/sIgE levels of peanuts and tree nuts increased significantly from initial diagnosis to the time patients were enrolled to the study. Moreover, many patients with initially negative SPT/sIgE grades to peanut and tree nuts were positive on enrollment. This may reflect the fact that peanut and tree-nut allergy is less likely to resolve with time compared with other foods $(5,26,27)$. Alternatively, it could reflect the development of allergy in some patients who were only slightly sensitized. The high rate of atopy in our patients $(80 \%$ had a history of AD and all had at least one food allergy) is similar to the population studied by Lack and colleagues (15), in which elimination of peanuts from the diet resulted in increased risk of developing IgEmediated peanut allergy. In our study, the rate of development of peanut allergy in patients with $\mathrm{AD}$ or egg allergy was higher (50\%) compared with the $34 \%$ found in the LEAP study for patients with positive SPT to peanuts. However, this is not surprising given the fact that our group of patients was a selective group with additional food allergies. Thus, tree-nut elimination in these high-risk patients appears to have a similar effect.

The retrospective design of this study and its reliance on parents' memories limit our findings. However, in most cases, the data, including physician notes, SPTs, and sIgE levels, were obtained directly from patients' medical records, providing additional support to the history obtained. In addition, this cohort comprises a selected group of patients with high levels of sensitization to multiple foods and high rate of positive OFCs as a result. Our findings should therefore be used to spark further investigations of additional less selected patients before general recommendations could be made.

The grading system we used for combining the SPT and sIgE levels is somewhat arbitrary and might be interpreted differently for each food, but it is based on previous studies. For example, an SPT wheal of $<1$ vs. $1-4$ vs. $>4 \mathrm{~mm}$ was used as the cutoff in the LEAP study, and the SPT thresholds predictive of a positive OFC are $>8 \mathrm{~mm}$ for most foods $(9,15,24,28)$. The sIgE was graded based on the ImmunoCAP grading. 


\section{Articles | Elizur et al.}

In summary, the present study provides a detailed description of reasons for initiating an elimination diet in a well-defined selected group of multiple-food-allergic patients.
This study raises several points. First, compared with most foods, elimination of tree nuts was based on low probability of actual allergy, without a previous reaction to the eliminated

Table 3. Characteristics of tree nuts eliminated from patients' diet

\begin{tabular}{|c|c|c|c|c|c|c|}
\hline Variable & Almond & Cashew & Hazelnut & Pecan & Pistachio & Walnut \\
\hline Ever eliminated, $n$ & 47 & 58 & 58 & 58 & 58 & 58 \\
\hline Male gender (\%) & 55.3 & 50 & 50 & 50 & 50 & 50 \\
\hline \multicolumn{7}{|l|}{ Race } \\
\hline Other (\%) & 6.4 & 6.9 & 6.9 & 6.9 & 6.9 & 6.9 \\
\hline Reaction ever (\%) ${ }^{\mathrm{a}}$ & 4.3 & 34.5 & 0 & 8.6 & 12.1 & 25.9 \\
\hline Reaction一skin $(\%)^{\mathrm{b}}$ & 100 & 78.9 & 0 & 80 & 71.4 & 78.6 \\
\hline OFC ever (\%) ${ }^{c}$ & 31.9 & 7 & 15.5 & 15.5 & 8.8 & 19 \\
\hline Positive OFC & $0 / 15$ & $1 / 4$ & $1 / 9$ & $1 / 9$ & $1 / 5$ & $1 / 11$ \\
\hline Food re-introduction (\%) ${ }^{d}$ & 34 & 5.2 & 12.1 & 13.8 & 8.6 & 15.5 \\
\hline Current elimination, $n$ & 31 & 55 & 51 & 50 & 53 & 49 \\
\hline
\end{tabular}

$\mathrm{Gl}$, gastrointestinal; Resp, respiratory; EPI, epinephrine.

$P$ value $<0.0033$ (after applying Bonferroni correction) is considered significant.

a Significant differences between cashew and almond, hazelnut, and pecan and between walnut and almond and hazelnut.

IInitial reaction and the percentage is of number of patients with reactions.

"Significant differences between cashew and almond.

dignificant differences between almond and cashew and pistachio.

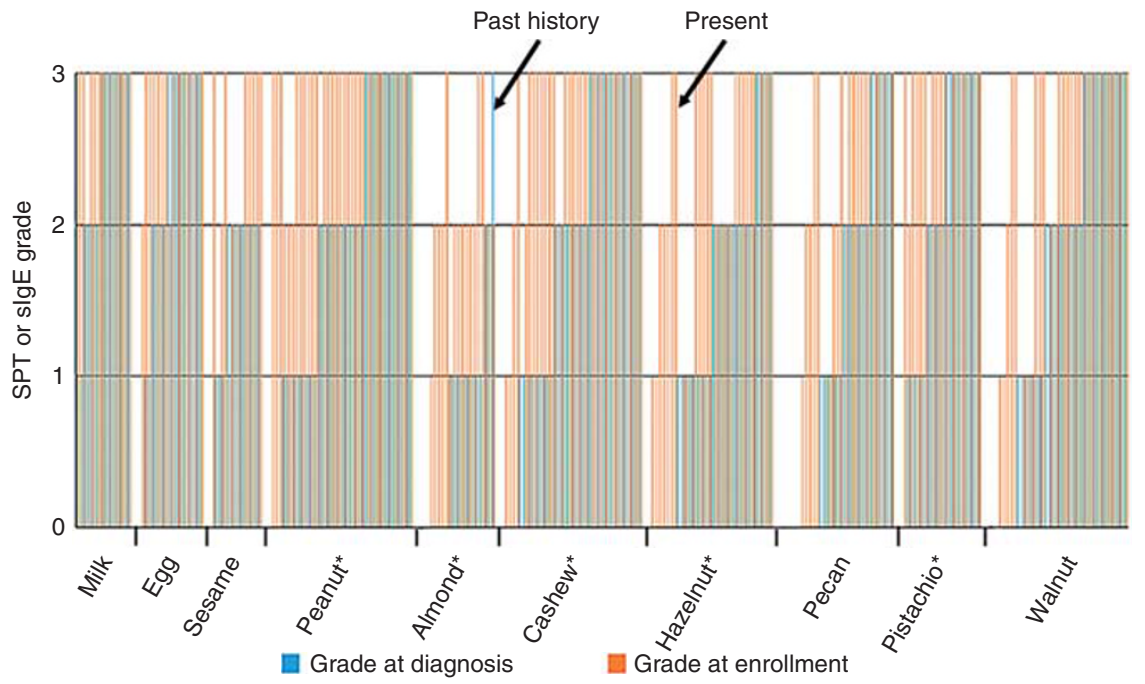

Figure 3. Change in SPT/slgE grade from time of diagnosis to study enrollment. Past SPT/slgE grades from the time the patients were diagnosed (light blue) were compared with their present levels (orange) for each individual food and for each patient. Gray represents overlapping values from both time points. *Statistically significant increases were noted for peanut, almond, cashew, hazelnut, and pistachio (see text for details). 


\section{Multiple tree-nut allergy $\quad$ Articles}

food, with low or even negative sensitization, and without performing an OFC. Second, sensitization levels, especially for tree nuts, increased over time, and most patients had OFCproven food allergy years later, suggesting that these food allergies developed over time.

\section{ACKNOWLEDGMENTS}

Jennifer B. Bollyky received her funding from the Sean N. Parker Center for Allergy and Asthma Research at Stanford University and Whitney M. Block, N.P. received her funding from the FARE Center of Excellence.

Disclosure: The authors declare no conflict of interest.

\section{REFERENCES}

1. Rona RJ, Keil T, Summers C, et al. The prevalence of food allergy: a metaanalysis. J Allergy Clin Immunol 2007;120:638-46.

2. Gupta RS, Springston EE, Warrier MR, et al. The prevalence, severity, and distribution of childhood food allergy in the United States. Pediatrics 2011;128:e9-17.

3. de Leon MP, Glaspole IN, Drew AC, Rolland JM, O'Hehir RE, Suphioglu C. Immunological analysis of allergenic cross-reactivity between peanut and tree nuts. Clin Exp Allergy. 2003;33:1273-80.

4. Maloney JM, Rudengren M, Ahlstedt S, Bock SA, Sampson HA. The use of serum-specific IgE measurements for the diagnosis of peanut, tree nut, and seed allergy. J Allergy Clin Immunol 2008;122:145-51.

5. Clark AT, Ewan PW. The development and progression of allergy to multiple nuts at different ages. Pediatr Allergy Immunol 2005;16:507-11.

6. Bergmann MM, Caubet JC, Boguniewicz M, Eigenmann PA. Evaluation of food allergy in patients with atopic dermatitis. J Allergy Clin Immunol Pract 2013;1:22-8.

7. Chang A, Robison R, Cai M, Singh AM. Natural history of food-triggered atopic dermatitis and development of immediate reactions in children. J Allergy Clin Immunol Pract 2016;4:229-236.e1.

8. Elizur A, Cohen M, Goldberg MR, Rajuan N, Katz Y. Mislabelled cow's milk allergy in infants: a prospective cohort study. Arch Dis Child 2013;98:408-12.

9. Sampson HA, Aceves S, Bock SA, et al. Food allergy: a practice parameter update-2014. J Allergy Clin Immunol 2014;134:1016-25.e43.

10. Boyce JA, Assa'ad A, Burks AW, et al. NIAID-Sponsored Expert Panel Guidelines for the diagnosis and management of food allergy in the United States: report of the NIAID-sponsored expert panel. J Allergy Clin Immunol 2010;126 (6 Suppl): S1-58.

11. Perry TT, Matsui EC, Conover-Walker MK, Wood RA. Risk of oral food challenges. J Allergy Clin Immunol 2004;114:1164-8.

12. Muraro A, Werfel T, Hoffmann-Sommergruber K, et al., EAACI Food Allergy and Anaphylaxis Guidelines Group. EAACI food allergy and anaphylaxis guidelines: diagnosis and management of food allergy. Allergy 2014;69:1008-25.

13. Christie L, Hine RJ, Parker JG, Burks W. Food allergies in children affect nutrient intake and growth. J Am Diet Assoc 2002;102:1648-51.

14. Arasi S, Otani IM, Klingbeil E, et al. Two year effects of food allergen immunotherapy on quality of life in caregivers of children with food allergies. Allergy Asthma Clin Immunol 2014;10:57.

15. Du Toit G, Roberts G, Sayre PH, et al. Randomized trial of peanut consumption in infants at risk for peanut allergy. N Engl J Med 2015;372: 803-13.

16. Du Toit G, Katz Y, Sasieni P, et al. Early consumption of peanuts in infancy is associated with a low prevalence of peanut allergy. J Allergy Clin Immunol 2008;122:984-1.

17. Nowak-Wegrzyn A, Assa'ad AH, Bahna SL, Bock SA, Sicherer SH, Teuber SS. Adverse reactions to Food Committee of American Academy of Allergy, Asthma \& Immunology. Work Group report: oral food challenge testing.. J Allergy Clin Immunol 2009;123 (6 Suppl): S365-83.

18. Bégin P, Dominguez T, Wilson SP, et al. Phase 1 results of safety and tolerability in a rush oral immunotherapy protocol to multiple foods using Omalizumab. Allergy Asthma Clin Immunol 2014;10:7.

19. Du Toit G, Roberts G, Sayre PH, et al. Learning early about peanut allergy (LEAP) study team. J Allergy Clin Immunol 2013;131:135-43 e1-12.

20. Peters RL, Allen KJ, Dharmage SC, et al. Skin prick test responses and allergen-specific IgE levels as predictors of peanut, egg, and sesame allergy in infants. J Allergy Clin Immunol 2013;132:874-0.

21. Burks AW, Tang M, Sicherer S, et al. ICON: food allergy. J Allergy Clin Immunol 2012;129:906-20.

22. Brough HA, Turner PJ, Wright $T$, et al. Dietary management of peanut and tree nut allergy: what exactly should patients avoid? Clin Exp Allergy 2015;45:859-71.

23. Caubet JC, Eigenmann PA. Allergic triggers in atopic dermatitis. Immunol Allergy Clin North Am 2010;30:289-307.

24. Clark AT, Ewan PW. Interpretation of tests for nut allergy in one thousand patients, in relation to allergy or tolerance. Clin Exp Allergy 2003;33:1041-5.

25. Ball H, Luyt D, Bravin K, Kirk K. Single nut or total nut avoidance in nut allergic children: outcome of nut challenges to guide exclusion diets. Pediatr Allergy Immunol 2011;22:808-12.

26. Byrne AM, Malka-Rais J, Burks AW, Fleischer DM. How do we know when peanut and tree nut allergy have resolved, and how do we keep it resolved? Clin Exp Allergy 2010;40:1303-1.

27. Elizur A, Rajuan N, Goldberg MR, Leshno M, Cohen A, Katz Y. Natural course and risk factors for persistence of IgE-mediated cow's milk allergy. J Pediatr 2012;161:482-7.e1.

28. Ho MH, Heine RG, Wong W, Hill DJ. Diagnostic accuracy of skin prick testing in children with tree nut allergy. J Allergy Clin Immunol 2006;117: 1506-8. 